\title{
Strontium isotopes in dental calculus \\ as a screening approach to investigate past human migrations: your (ancient) trash in my treasure
}

\author{
ANTHONY DOSSETO ${ }^{1}$, LAURA WEYRICH ${ }^{2}$ AND \\ RAPHAEL EISENHOFER PHILIPONA ${ }^{3}$ \\ ${ }^{1}$ University of Wollongong \\ ${ }^{2}$ PennState University \\ ${ }^{3}$ University of Adelaide \\ Presenting Author: tonyd@uow.edu.au
}

Strontium ( $\mathrm{Sr}$ ) isotopes in teeth have been a valuable tool to study past human migrations and animal dietary range. Although only a small amount of enamel is required for analysis (a few $\mathrm{mg}$ ), it can be challenging to obtain permission to undertake destructive analysis of fossil teeth. Dental calculus is often present with fossil teeth, and more readily available for destructive analysis, offering an opportunity to derive information on past populations without impacting precious archaeological collections.

We have investigated how the $\mathrm{Sr}$ isotope composition of calculus compare to that of the corresponding tooth. We analysed calculus both in-situ (by laser ablation multi-collector ICP-MS) and in solution (after isolating the $\mathrm{Sr}$ fraction by chromatography); enamel and dentine for the corresponding teeth were analysed in-situ. In-situ $\mathrm{Sr}$ isotope ratios in calculus are higher or similar to the corresponding enamel and dentine. Solution analysis of calculus shows that $\mathrm{Sr}$ isotope ratios are also higher than (or similar to) those in the corresponding enamel or dentine, thus ruling out $\mathrm{Rb}$ as the cause of these higher values. Higher $\mathrm{Sr}$ isotope ratios could reflect diagenesis and incorporation of soil $\mathrm{Sr}$ with high values post-burial. Solution analysis of calculus shows $\mathrm{Mn} / \mathrm{Ca}$ ratios at least 20 times greater than in corresponding teeth, supporting this hypothesis.

Overall, although calculus is more diagenetically altered than enamel, the difference between $\mathrm{Sr}$ isotope ratios in calculus determined in solution and in corresponding enamel is two orders of magnitude smaller than the range of values typically encountered in the environment and in enamel from archaeological sites (although it depends on the region considered). These observations suggest that calculus could provide some preliminary information on the $\mathrm{Sr}$ isotope composition of an individual; although analysis of enamel would still be recommended. The difference between $\mathrm{Sr}$ isotope ratios in calculus determined in-situ and in corresponding enamel is also small; suggesting that in-situ analysis of calculus (much more rapid than solution analysis: 1 day compared to $\sim 1$ week) could be used as a screening method to estimate the $\mathrm{Sr}$ isotope composition of an individual. 